\title{
Design and Development of a Horizontal CTE Curriculum to Prepare Students for the New Manufacturing Economy (Work in Progress)
}

\author{
Ketan Thakare, Texas A\&M University \\ Mr. Osazuwa John Okundaye Jr, Texas A\&M University
}

Osazuwa is a first year PhD student at Texas A\&M University. He is a part of the Texas A\&M Embodied Interaction Lab (TEILab). His research is motivated by the idea of an embodied conception of the mind. He comes from an interdisciplinary background having earned a Bachelor's degree in psychology and a Masters of Science in Visualization afterward. He is versed in engaging the theoretical aspects of HumanComputer Interaction while able to engage in computer graphics applications (computer-aided design, modeling, animation, and 3D fabrication) and concepts pertaining to Computer Science.

Miss Qing Li, The Embodied Learning \& Experience LAB

Qing Li is a student who has backgrounds in both education and IT, and she is interested in using interaction techniques to support teaching and learning.

\section{Dr. Malini Natarajarathinam, Texas A\&M University}

Dr. Malini Natarajarathinam joined the faculty of Industrial Distribution Program at Texas A\&M University in 2007. Natarajarathinam received her Ph.D. in Supply Chain Management from The University of Alabama. She received her Bachelor of Engineering (Major: Industrial and Systems Engineering) from Anna University [Tamilnadu, India], her MS in Industrial Engineering from Auburn University, her MA in Management Science and MS in Applied Statistics from The University of Alabama. She has experience working with many industries such as automotive, chemical distribution etc. on transportation and operations management projects. She works extensively with food banks and food pantries on supply chain management and logistics focused initiatives. Her graduate and undergraduate students are integral part of her service-learning based logistics classes.

She teaches courses in strategic relationships among industrial distributors and distribution logistics. Her recent research focuses on engineering education and learning sciences with a focus on how to engage students better to prepare their minds for the future. Her other research interests include empirical studies to assess impact of good supply chain practices such as coordinated decision making in stochastic supply chains, handling supply chains during times of crisis and optimizing global supply chains on the financial health of a company. She has published her research in Journal of Business Logistics, International Journal of Physical Distribution and Logistics Management and peer-reviewed proceedings of the American Society for Engineering Education.

\section{Dr. Sharon Lynn Chu, University of Florida}

Dr. Chu received her B.Soc.Sci (1st Class Honors) in Communication and New Media from the National University of Singapore, her MS in Computer Science \& Applications and a graduate certificate in Human-Computer Interaction from Virginia Tech, and her Ph.D in Human-Computer Interaction from Texas A\&M University. She is the Director of the ELX (Embodied Learning \& Experience) Lab. The ELX Lab conducts research in two main areas: cyberlearning and technologies for mental health.

\section{Dr. Mathew Kuttolamadom, Texas A\&M University}

Dr. Mathew Kuttolamadom is an associate professor in the Department of Engineering Technology \& Industrial Distribution and the Department of Materials Science \& Engineering at Texas A\&M University. He received his Ph.D. in Materials Science \& Engineering from Clemson University's Int'l Center for Automotive Research. His professional experience is in the automotive industry including at the Ford Motor Company. At TAMU, he teaches Mechanics, Manufacturing and Mechanical Design to his students. His research thrusts include bioinspired functionally-graded composites, additive/subtractive manufacturing processes, laser surface texturing, tribology, visuo-haptic VR/AR interfaces and engineering education. 


\section{ASEE ANNUAL CONFERENCE}

Virtual Meeting | July 26-29, 2021 | Pacific Daylight Time

.

\section{Prof. Francis Quek, Texas A\&M University}

Francis Quek is a Professor at Texas A\&M University (Visualization, and Computer Science and Engineering and Psychology - by courtesy). He joined Texas A\&M University as an interdisciplinary President's Signature Hire to bridge disparities in STEM. Formerly he has been the Director of the Center for Human-Computer Interaction at Virginia Tech. Francis received both his B.S.E. summa cum laude (1984) and M.S.E. (1984) in electrical engineering from the University of Michigan. He completed his Ph.D. in Computer Science at the same university in 1990. Francis is a member of the IEEE and ACM. He performs research in Human-Computer Interaction (HCI), learning sciences and technology, embodied interaction, embodied learning, HCI for accessibility (especially for individuals with blindness), multimodal verbal/non-verbal interaction, multimodal meeting analysis, vision-based interaction, multimedia databases, medical imaging, assistive technology for the blind, human computer interaction, computer vision, and computer graphics. http://teilab.tamu.edu 


\section{Design and Development of a Horizontal CTE Curriculum to Prepare Students for the New Manufacturing Economy (Work in Progress)}

\section{Background}

How we educate students is highly influenced by the kind of work that we envision for them [1]. Economies of the future will favor individuals who possess flexibility across multiple competencies and can grow and learn with the evolving workplace [2]. To prepare students for such a future workspace of flexible high-mix short-run production, the learning experience needs to be designed to integrate knowledge/skills across multiple technology areas within an authentic practice. Career and Technical Education (CTE) program in high schools provides a platform to do this. The development of such a CTE course, which intends for students to develop a holistic understanding of a range of technologies, is grounded in the theory of expansive learning. As proposed by Engestrom [3], expansive learning is a theory of organizational learning that emphasizes horizontal expertise which is "capacity to move between activity contexts and to engage in the exchange and mixing of domain-specific expertise". In order to operationalize the horizontal expertise development in the CTE course, a de-scaffolding approach will be used. Descaffolding approach involves students developing expertise on a 'in-focus' topic while other 'out-of-focus' topics are scaffolded, and over time 'out-of-focus' topic incrementally start coming into focus as the previously 'in-focus' topic is scaffolded [4].

\section{Objective}

The broad objective of developing and implementing a horizontal CTE curriculum is to understand how an integrated horizontal learning approach in which students combine learning of basic engineering skills, production, and manufacturing processes, with the deployment of work products, may develop holistic technology understanding and STEM identities. Also, within the context of Engineering education, the proposed research aims to understand how horizontal expertise development may be operationalized through a de scaffolding process. Furthermore, within the context of CTE, the research aims to generate insights on how curricula may be designed to effectively prepare high school students for careers in engineering and engineering innovation and design.

\section{CTE Course and Class Organization}

In order to achieve the objectives of the proposed research, the authors, part of a research group at Texas A\&M University, have developed a curriculum for a CTE course, with the support of grant funded by National Science Foundation through ITEST Program. The developed CTE course is being taught at the new CTE Center in Bryan Independent School District (BISD), TX. The CTE class consists of 18 high school juniors and is organized into two groups (with the strength of 11 and 7 students). Each of the groups is taught two days a week for 3 hours

\section{Course Development}

4.1. Justification for Course Content and Delivery

The course content was designed to help students develop competencies spanning the prototyping of one technology entity to the production of many - all within a context that enables the students to see the relevance of and connections across these technologies and processes. For 
students to learn prototyping, engineering technologies included in the course were digital fabrication, micro-computer-based electronics, and programming. The course includes topics on production processes so students learn how to mass-produce the prototype and topics on production management for students to learn how to manage the mass manufacturing of designed prototype. The strategy adopted while teaching students the engineering technologies was to teach students the theoretical concepts followed by the application of these concepts through inclass small projects and exercises so students understand the concepts and are able to apply the tools for prototyping. In order to teach topics of production processes and production management, theoretical concepts were explained followed by discussing practical application of these concepts in real-life manufacturing industry scenarios so that students understand the context in which these concepts are applied along with their application while performing the mass-production.

\subsection{Course Description}

\subsubsection{Year 1}

Year 1 of the course will be focused on Operational/Tactical Knowledge and Skills of the engineering components and production processes to serve an authentic community-focused goal of preparing hands-on kits for science learning and supporting their deployment in a local elementary school. Table below provides an overview of in focus and scaffolded topics that will be covered in semesters 1 and 2 of Year 1 . There are three cycles per semester and each cycle is of six weeks.

\subsubsection{Semester 1:}

Manufacturing Planning and Control:

Students were introduced fundamental concepts related to manufacturing processes and control. In context of this course, the term manufacturing, and related terms of production, refers to 'making of many'. The topics covered were: introduction to manufacturing systems, Master Production Schedule, Material Requirement Planning, Inventory Management and Control, and Introduction to Lean Production. The scaffolded aspects of electronics and digital fabrication were covered through the examples (e.g., mass manufacturing of LED lights for decoration purpose) given when discussing the manufacturing concepts. Instructors taught students each electronics concept by initial exposure to theoretical concepts (e.g., Instructors introduce students to the concept of master production schedule by explaining the importance of scheduling to meet production goals in manufacturing setting, and giving high-level explanation on how to construct such a schedule based product assembly and goal duration) and were then given an exercise to connect theory to practice (e.g., students making a schedule to complete a mock production run of making 100 sandwiches in 4 hours).

Electronics and Programming:

Students were given a high-level introduction to electronics (e.g., Ohm's law). In support of these concepts, students work with analog tools such as breadboards, multimeters, power supplies, wires, or soldering irons. Students engaged in electronic fabrication by first using breadboards to test circuit designs. Students completed their circuit designs by applying solder to components together via copper tape, cardboard, and customized wires made via crimping connectors and applying heat shrink. The concepts of manufacturing were scaffolded while discussing the mass production of designed electronics prototypes (e.g., material requirement 
plan to procure raw material quantities to manufacture 100 units of clap activated light switch). Students applied their electronics skills by creating switches and connectors for use across different project settings. In addition, students developed a production schedule to manufacture thousand units of such paper switches.

\subsubsection{Semester 2:}

Digital Fabrication:

Students will learn how to use basic shop/power tools and 3D printers. Instructors will teach students basic CAD CAM skills (e.g., camera space manipulation, model transformation, boolean modeling techniques, and consideration of real-world dimensions for eventual fabrication). The concepts of production management (e.g., quality management while 3D printing, supply chain in online 3D printing service) will be scaffolded while teaching concepts related to digital fabrication. Students will be first taught the basics of operating the CADCAM program such as using the boolean tool to create new models by either adding or subtracting geometry. Following which, students will be given a small assignment to apply their knowledge (e.g., use the boolean tool to create a key through the addition and subtraction of primitive geometry in the workspace).

Production Management

Students will be given a high-level introduction to production management including quality management, sales and operations planning, forecasting, customer service, and basics concepts of supply chain management. The scaffolded aspects of electronics and digital fabrication will be covered through the examples (e.g., overview of supply chain for commercial, custom $3 \mathrm{~d}$ printing service, quality control in mass-manufacturing of electronics) given when discussing the production management concepts. Students will be taught by initial exposure to theoretical concepts (e.g., demand forecasting) and are then given an applied example that connects theory to practice (e.g., application of demand forecasting by big stores to predict demand of seasonal goods and order stock). In-class exercises will be given for students to apply the basic concepts of production management (e.g., forecasting coffee demand based on historical sales using basic quality control charts like $\mathrm{X}$ bar, and $\mathrm{R}$ chart).

\subsubsection{Year 2:}

Year 2 of the course will focus on Tactical/Strategic Knowledge and Skills where student move from production to design, innovation, and entrepreneurship. Semester 1 of year 2 will focus on students doing end-to-end production of kits for elementary schools. In addition, students will act as consultants in designing products for local businesses for low-volume, high variability production scenario. The students will apply skills learned in semester 1 and semester 2 to come up with design solutions. In semester 2 , the students act as consultants to help produce the products using the design proposed in semester 1. The challenge projects for students to work on are currently being decided with assistance from a local business incubator.

\subsection{Course Evaluation}

The students' understanding of concepts will be evaluated by tests administered after teaching of a new topic (e.g., material requirement planning in manufacturing planning and control, boolean modeling techniques in digital fabrication). The tests will be composed of short answer questions (e.g., multiple-choice, true-or-false, fill-in-the-blanks) and extended answer questions (e.g. 
explain-the-concept, discuss-with-example). In addition, a group discussion of case study scenarios (e.g., set up production process for making cloth masks) will be conducted to evaluate students' ability to effectively apply learned principles. Furthermore, we will employ instruments like the Academic Self-Description Questionnaire II (ASDQ-II) and the Scientific Possible Selves Inventory are the instruments to examine students' STEM identity development throughout the course. The Academic Self-Description Questionnaire II (ASDQ-II) [5] includes a subscale of science self-concept that includes 8 items that assess identification with and perceived efficacy in science (e.g., "Compared to others my age I am good at COMPUTER STUDIES classes"). The Scientific Possible Selves Inventory [6] includes four subscales related to STEM identity: i) hoped-for scientific possible selves (e.g., "I expect to go to college and get a degree needed for a job in science"), ii) expected scientific possible self (e.g., "I am confident that I can get better grades than other students in science classes"), iii) feared scientific possible selves (e.g., "I worry that I will not get good grades in science classes"), and iv) strategies and plans related to science possible selves (e.g., "I want to take as many science classes as possible next year").

4. Preliminary results and analysis

Two focus groups were conducted before and after semester 1 of the CTE course work via remote teleconferencing (i.e., Zoom) in compliance with COVID-19 guidelines of BISD. Video and audio data were collected for the focus groups. Each focus group followed a semi-structured format where mentors ask a pre-defined sequence of questions regarding Making and Manufacturing, diving deeper into questions based on participants' responses. We asked three types of questions to initiate the discussion on the Making and Manufacturing, along with identity-focused questions to gauge students' self-efficacy. Qualitative data analysis was conducted on transcribed video data and notes. Qualitative coding followed a grounded theory approach as employed by Charmaz and Strauss [62]. The coding procedure was conducted by a team of three coders. After completion of open coding by a single coder, the other 2 coders reviewed the codes generated. The inter-rater agreement was at $90.3 \%$.

The increase in the students' knowledge of electronics and programming after the course was evident from students being able to exactly identify the tools and components needed for Making and justify their choices. Before the course, students had some level of familiarity with the components needed to build objects such as PCs, watches, shoes, or robots but were not quite able to describe specifically what types of components they would need (Instructor: "Okay. Alright so let's- so with that in mind, what would you need to make, what would you need to make any of these things I just mentioned right now?" Student 1: Material? Instructor: "Yeah, so for example we did like for example on the case of the PC what stands out to you that we, what we would need to make that?" Student 1: "Motherboard. We need the shell. The fan. The battery. Some wires.” Student 2: “Obviously, electricity. Obviously, power supply."). After exposure to the course, in the second focus group, one group expressed interest in making an RC boat and incorporated their familiarity with Arduinos to describe closer what they need and why for the product (Student: "We need to know how to do coding ... we need a mold for the boat we need a motor, we need to begin for me that is the power, about.").

Similarly, students' level of knowledge and understanding of manufacturing concepts had grown after the course. In the first focus group, students had a cursory knowledge of manufacturing 
concepts but they lacked familiarity with terminology, the description was vague, and lacked logical grounding. (e.g., Instructor: Suppose you need to order and store raw material for making 10000 masks, what will be your strategy? Student: Start with the tracking how much you will need for a batch you make... we probably need to have the means to transport things back and forth from a warehouse or have the warehouse be on site.). In the second focus group, based on the answers provided for a question about a hypothetical mass-manufacturing scenario, students demonstrated familiarity with terminology, clarity in the description, and logical organization of the process. (e.g., Instructor: Supposed you are tasked with manufacturing 10000 skateboards in one month, what will be your raw material ordering and storage strategy? Student: In that case, we should order the raw materials bi-weekly, and that our maximum storage capacity should be 5000 for the material so as to ensure economy of space).

5. Conclusion and next steps

A 2-year (4 semesters) CTE course operationalizing horizontal learning through de-scaffolding has been developed and results from the first semester indicate that the course is effective in helping students develop multiple competencies simultaneously. While delivering the remaining part of the course, we plan to observe, measure, and analyze how the students' knowledge in subsequent semesters is carry-forwarded to the next semesters. The conclusions from this analysis will be used to make modify the curriculum to make it more effective. We plan to make our findings and developed curriculum available for broad dissemination to precollege science and engineering educators through publication on websites, presentations at educational conferences, and other professional development workshops.

References:

1. Pihlaja, J., Learning in and for production: An activity-theoretical study of the historical development of distributed systems of generalizing, in Behavioural Sciences. 2005, University of Helsinki.

2. Wang, Y., Education in a changing world: Flexibility, skills, and employability. World Bank, 2012.

3. Engeström, Y., R. Miettinen, and R.-L. Punamäki, Perspectives on activity theory. 1999: Cambridge University Press.

4. Dennen, V.P., Cognitive apprenticeship in educational practice: Research on scaffolding, modeling, mentoring, and coaching as instructional strategies. Handbook of research on educational communications and technology, 2004. 2(2004): p. 813-828.

5. Marsh, H.W., The structure of academic self-concept: The Marsh/Shavelson model. Journal of Educational psychology, 1990. 82(4): p. 623.

6. Beier, M.E., L.M. Miller, and S. Wang, Science games and the development of scientific possible selves. Cultural studies of science education, 2012. 7(4): p. 963978. 